\title{
Políticas de esporte escolar e a construção social do currículo de Educação Física
}

\author{
Alvaro Rego Millen Neto ${ }^{1}$ \\ Alexandre da Costa Ferreira ${ }^{1}$ \\ Antonio Jorge Gonçalves Soares ${ }^{2}$ \\ ${ }^{1}$ Universidade Gama Filho, Rio de Janeiro, RJ, Brasil \\ ${ }^{2}$ Universidade Federal do Rio de Janeiro, Rio de Janeiro, RJ, Brasil
}

\begin{abstract}
Resumo: $O$ estudo descreve e analisa como os Jogos Estudantis influenciam a construção social do currículo de uma escola municipal do Rio de Janeiro. Também localiza os discursos (ideologias) veiculados com a participação da escola nesses eventos. Para a coleta de dados foram utilizadas entrevistas com os professores envolvidos e observações etnográficas das oficinas esportivas e dos jogos. Os resultados permitem considerar que o discurso do rendimento esportivo contribui para a legitimação da educação física na escola investigada e também para o reconhecimento da excelência da própria escola. Outrossim, as ações pedagógicas concentram-se nos resultados e não na formação de todos os alunos.
\end{abstract}

Palavras-chave: Esportes. Educação Física. Currículo.

\section{Policies for school sports and the social construction of the physical education curriculum}

Abstract: This study describes and analyzes how the Students Games influence the social construction of a Rio de Janeiro municipal school curriculum. It also recognizes the announcements (ideologies) conduced with the school's participation in these events. For data collection interviews with the teachers involved and ethnographic observations of the sports offices and of the games were applied. The results let us consider that the discourse of the sports efficiency contributes to the legitimation of the physical education at the investigated school and also for recognition of the school itself excellence. Likewise, the pedagogical activities focus on results and not in all student's education.

Key Words: Sports. Physical Education. Curriculum.

\section{Introdução}

Ao pensarmos nos elementos de legitimação da educação física enquanto componente curricular da Educação Básica, diferentes discursos/vozes podem ser localizados. Historicamente, creditou-se à educação física papeis sociais relacionados a determinadas instituições. Bracht (1992) localizou esses elementos de legitimação em torno dos seguintes discursos/vozes: o higiênico e a idéia de promoção da saúde; o militar e a formação de um homem forte e respeitador das normas sociais; e o esportivo e a concepção de seleção de talentos e formação de atletas. Em função da constante reconfiguração do cenário sociocultural, algumas dessas vozes perderam potência com o passar dos anos, outras ainda se fazem ouvir e novas surgiram.

O discurso relacionado à atividade física enquanto instrução militar passou a ser alvo de críticas desde que o país deixou de ser governado por um regime de exceção. A promoção da saúde mantém-se estável enquanto uma voz representativa da educação física no meio escolar e, de certo modo, foi reforçada na sociedade com o movimento chamado de novo higienismo (GOIS JUNIOR, 2003). O ideal esportivo, que se desenvolveu notavelmente no Brasil nos anos de 1960 e 1970, continua forte e ainda é o principal elemento legitimador da educação física escolar. A voz intrínseca dos assuntos pedagógicos, relacionada ao papel da escola e a consequente contribuição da educação física na formação de um homem crítico, autônomo e emancipado, iniciou-se na primeira metade dos anos de 1980 e se faz ouvir com mais ênfase nas duas últimas décadas. A ideia da educação para o lazer surgiu, no mesmo contexto do pensamento crítico, como mais uma voz a se relacionar com a educação física na escola (MARCELLINO, 1987).

Sobre o discurso crítico da educação física, vale ressaltar que, a partir dos anos de 1980, houve um significativo desenvolvimento da produção acadêmica que tem como objeto a educação física na Educação Básica. Algumas dessas obras tinham como alvo desconstruir antigos projetos de educação física e apresentar 
novos ideais, novas perspectivas teóricas e, em alguns casos, novas metodologias de ensino. Sem a pretensão de esgotar as publicações que foram importantes para essa virada paradigmática, lembramos aqui as seguintes contribuições das décadas de 1980 e de 1990: Medina (1983), Oliveira (1983, 1985), Costa (1987), Tani et al. (1988), Freire (1989), Betti (1991), Kunz (1991, 1994), Resende (1992), Bracht (1992), Soares et al. (1992), Lovisolo (1995), Daolio (1995, 1998), Brasil (1998) e Darido (1999).

Quando localizamos esses discursos legitimadores na sociedade contemporânea, não podemos ser ingênuos em acreditar que o meio escolar está imune aos processos de reflexibilidade $^{1}$. Ou seja, a escola é um espaço concreto de reflexibilidade das manifestações da cultura corporal de movimento presentes em nossa sociedade. Assim, o esporte, a competição esportiva, a estética corporal, a saúde, o lazer e a formação humana são vozes recorrentes no diaa-dia da escola e presentes nas falas e anseios dos alunos e alunas. Na escola investigada, nosso campo de observação, esse diálogo foi travado com os fenômenos do esporte e da atividade física no seio da escola. Tais fenômenos não são objetos de reflexão que aparecem somente nas aulas regulares - no currículo "oficial" - da disciplina de educação física, mas também em outros momentos do cotidiano escolar: jogos e brincadeiras realizadas nos recreios e tempos vagos, oficinas de esportes, treinamento das equipes esportivas, competições esportivas, oficinas de dança, entre outros.

Durante o período de pesquisa de campo, verificamos que esses momentos destinados às práticas corporais, juntamente com a cultura discente, com a história de vida dos professores, com Projeto Político Pedagógico (PPP) da escola e com os planejamentos anuais, são os fios condutores (veículos) responsáveis pela difusão das "vozes" que legitimam a educação física na escola investigada. Dentre essas vozes que ecoam no cotidiano, a formação esportiva difundida pelo "veículo" da competição escolar parece ser a mais audível na constituição do

\footnotetext{
${ }^{1}$ No sentido de Giddens (2002), a reflexibilidade é um dos aspectos do dinamismo da modernidade e envolve a incorporação rotineira de novos conhecimentos e informações em situações que são reconstruídas e reorganizadas em outros contextos.
}

currículo da educação física no interior dessa escola.

Ao longo de sua história, a escola investigada participou de diversas competições esportivas escolares: Copa Intercolegial Dan'up, Copa Fanta, Jogos Bingo Arpoador, entre outras. Porém, nenhuma delas é considerada tão emblemática para a instituição como os Jogos Estudantis da Cidade do Rio de Janeiro. Desde o início de sua participação nesses jogos, em 1993, a instituição vem obtendo resultados expressivos, de tal modo que essa participação tem repercutido não só dentro dos muros da escola, mas também para além desses limites.

Nesse contexto, não foram raras as vezes que o trabalho esportivo realizado na escola foi destacado, seja em jornais de grande circulação, ou na revista publicada pela Secretaria Municipal de Educação - distribuída periodicamente para as escolas da rede. $E$, não é somente através dos registros nessas publicações que se propaga 0 sucesso da escola. É comum em conversas entre professores, pais e alunos de outras instituições da rede, ser destacada a qualidade do ensino oferecido na escola investigada. ${ }^{2}$ Ressaltamos que a projeção alcançada pelas instituições escolares no âmbito esportivo, não raro, as destacam no "mercado escolar". E, artifícios ideológicos são utilizados por algumas instituições, notadamente as privadas, que agregam, através da mídia, suas conquistas esportivas à excelência do ensino oferecido.

No caso da escola investigada, o reconhecimento social veiculado pelos resultados obtidos ao longo das várias edições dos Jogos Estudantis fez com que a voz da formação esportiva canalizada para a competição fosse reforçada em seu cotidiano. Nesse cenário, todos os atores envolvidos no processo têm sua cota de valorização. A direção vê o nome da escola destacado positivamente entre as demais escolas municipais; professores alcançam projeção para fora dos muros da escola e também são reconhecidos dentro da comunidade escolar; e, por fim, os alunos que se destacam fazendo parte das equipes representativas têm seus feitos reconhecidos pela comunidade.

A partir da problemática apresentada, o estudo tem o escopo de descrever e analisar como os 
Jogos Estudantis se inserem no processo de construção social do currículo (GOODSON, 2008) da educação física na escola investigada. Também pretende localizar as vozes (ideologias) que são veiculadas pelos Jogos Estudantis (dentro e fora da escola).

\section{Metodologia}

Para compreender como os Jogos Estudantis se inserem no processo de construção social do currículo da educação física na escola investigada foi realizado um estudo qualitativo de cunho etnográfico ${ }^{3}$. Os dados foram coletados através de entrevistas com os professores de educação física envolvidos com os jogos e de observações participantes do cotidiano escolar - notadamente das oficinas de esportes e da participação dos alunos nos Jogos Estudantis. Para dar tratamento aos dados foi utilizada a análise de conteúdo ${ }^{4}$.

O período de pesquisa de campo perdurou de 20 de agosto de 2008 a 19 de dezembro desse mesmo ano. E, durante esse período observamos 12 dias de oficinas de esportes, 15 treinamentos das equipes esportivas e 25 recreios, além dos dias que acompanhamos as equipes esportivas em eventos realizados fora da escola.

Em plena rotina da escola no segundo semestre de 2008, durante as observações etnográficas, identificamos os diálogos e narrativas que privilegiavam a realidade do que era vivido pelos sujeitos, propondo interpretações particulares daquele mundo, sem intenção de serem verdadeiras ou falsas, mas situadas naquele contexto cultural.

2 Um dos autores do presente texto faz parte do corpo docente da Secretaria Municipal de Educação do Rio de Janeiro e vivencia esse discurso.

${ }^{3}$ Para Geertz (1989, p. 33-34), é importante que este tipo de pesquisa seja produzida "por um trabalho de campo quase obsessivo de peneiramento, a longo prazo, principalmente qualitativo, altamente participante e realizado em contextos confinados, que os megaconceitos com os quais se aflige a ciência social contemporânea - legitimamente, modernização, integração, conflito, carisma, estrutura, significado - podem adquirir toda espécie de atualidade sensível que possibilita pensar não apenas realista e concretamente sobre eles, mas, o que é mais importante, criativa e imaginativamente com eles".

4 Segundo Bauer (2002) a análise do conteúdo é um método de análise textual desenvolvido dentro das ciências sociais empíricas para produzir inferências de um texto focal para seu contexto social de maneira objetivada. Este autor salienta que a validade da análise do conteúdo não deve ser julgada como uma "leitura verdadeira" do texto, mas em termos de sua fundamentação nos materiais pesquisados e sua congruência com a teoria do pesquisador, e a luz de seu objetivo de pesquisa, pois um texto possui diferentes leituras, dependendo dos vieses que contenha.
A pesquisa está cadastrada no Conselho Nacional de Ética em Pesquisa (CAAE 2885.0.000.312-08) e foi submetida ao Conselho de Ética em Pesquisa Envolvendo Seres Humanos da Universidade Gama Filho, CEPq/UGF, obtendo aprovação através do parecer $n^{\circ}$ 046.2008.

\section{O Cenário Do Estudo}

A escola investigada pertence à $7^{\text {a }}$ Coordenadoria Regional de Ensino (CRE) da Secretaria Municipal de Educação do Rio de Janeiro, que além dessa unidade possui mais 126 sob sua coordenação.

A escola possui um prédio com dois andares que abriga 13 salas de aula, um auditório com capacidade para 328 pessoas e as demais instalações que permitem seu funcionamento. Ressalta-se que todas as edificações estão em bom estado de conservação. Na parte externa do prédio principal da escola encontra-se uma quadra coberta, um pátio coberto e um pequeno campo de terra. A quadra coberta é cercada por tela, tem o piso de cimento sem irregularidades e as linhas que demarcam os espaços de jogo do basquetebol, do voleibol, do handebol e do futsal estão nítidas. O pátio, apesar de espaçoso aproximadamente 12 metros de comprimento por 10 de largura - possui diversas colunas de sustentação, o que dificulta o deslocamento dos alunos durante a prática de atividades físicas. Já o campo de terra batida, com dimensões de quatro metros de largura por 10 de comprimento, fica localizado entre o pátio e o muro que separa a escola de um condomínio de casas.

No ano letivo de 2008 o corpo discente foi constituído de 1181 alunos, distribuídos em quatro turmas do $6^{\circ}$ ano de escolarização, oito do $7^{\circ}$, oito do $8^{\circ}$ e seis turmas do $9^{\circ}$ ano. $O$ corpo docente da instituição é constituído por 54 professores, sendo cinco desses da disciplina educação física.

\section{As oficinas de esportes}

$\mathrm{O}$ espaço e o tempo dedicado às oficinas de esportes surgiram a partir do momento que a escola iniciou sua participação nos Jogos Estudantis organizados pela Secretaria Municipal de Educação do Rio de Janeiro, em 1993. No ano de 2008, essas oficinas foram desenvolvidas aos sábados, de 09h30min às $15 \mathrm{~h}$.

No contexto investigado, os responsáveis diretos pela realização dessas oficinas foram os professores Márcia e Luciano. Para tal, esses 
professores receberam uma carga horária extraordinária em seus regimes de trabalho. Assim, o início do funcionamento das oficinas esportivas oferecidas na escola investigada esteve condicionado, em 2008, à autorização desse acréscimo de carga horária. $O$ processo de autorização da carga horária não foi imediato, com isso houve um hiato temporal entre o início das aulas e o início das atividades das oficinas. Essas últimas começaram somente no mês abril.

Cabe destacar que a política administrativa da Secretaria Municipal de Educação do Rio de Janeiro não concede carga horária extra para esse tipo de atuação, em atividades que não sejam de caráter compulsório no currículo escolar. Nesse sentido, a escola recebeu a dotação dessa carga horária extra em função da representação positiva que possui no município do Rio de Janeiro. Os resultados da escola obtidos nos Jogos Estudantis trabalham ideologicamente no sentido de garantir esse tipo de exceção.

Após a autorização da carga horária extra, que possibilitou o início das atividades, foi realizado um trabalho de divulgação interna através da afixação de cartazes para toda comunidade. E, nesse mesmo período, foi promovido um processo seletivo com os alunos interessados. Essa seleção ocorreu nos moldes das conhecidas "peneiras" utilizadas pelos clubes de futebol, principalmente nas categorias de base. Os alunos foram organizados em equipes e participaram de jogos da modalidade para a qual se candidataram. O professor observador escolheu os alunos que apresentaram melhor desempenho e habilidade de acordo com as modalidades esportivas. Não observamos baterias de testes físicos ou outros critérios para a seleção. Segundo os professores responsáveis pelas oficinas, essa seleção sempre acontece em função da relação desproporcional entre 0 número de vagas oferecidas e o número de alunos que buscam participar das oficinas.

Sobre esse discurso do reduzido número de vagas $e$ a consequente necessidade de selecionar alguns alunos, podemos inferir algumas considerações. Em primeiro lugar fica a pergunta de base: a que interesse essas oficinas de esporte estão servindo? Se for ao interesse da formação educacional dos alunos, faz sentido restringir o número de vagas? Faz sentido lançar mão dos mesmos critérios de seleção utilizados nas peneiras do esporte de alto rendimento, que privilegiam o aspecto do rendimento?

Quando pensamos nessas questões fica claro que o principal interesse não é a formação de todos os alunos da escola nessa experiência curricular, mas apenas a formação e aprimoramento dos alunos que já possuem bom desempenho esportivo. Todavia, não podemos pensar na construção de experiências curriculares totalitárias que obriguem compulsoriamente a todos participarem de tudo na vida escolar. O que está em questão aqui é saber qual o tratamento pedagógico que é dado aos não escolhidos. Nas observações de campo não foi visto nenhum tipo de trabalho com os não selecionados, apesar do clima de solidariedade e identidade que reina em torno das equipes. Com isso pode-se inferir que a escola, nessa experiência pedagógica, em pouco se afasta da lógica do esporte alto rendimento, na medida em que seleciona os alunos/atletas que já dispõem de habilidades. Obviamente, se o principal interesse for a formação (esportiva) dos alunos, a seleção não deve pautar-se nos critérios do alto rendimento, mas no interesse $e$ necessidade dos alunos. $\mathrm{Na}$ escola também deveria valer a lógica inversa. Os alunos que têm mais dificuldade em determinada modalidade esportiva e desejam participar da vida esportiva da escola também deveriam ser beneficiados com o reforço da aprendizagem esportiva.

Se analisarmos o que está em jogo, o uso ideológico do esporte alude a duas possibilidades de interesses que permeiam essa dinâmica. A primeira, mais óbvia, diz respeito à manutenção de uma representação positiva da escola investigada no cenário das escolas municipais da cidade do Rio de Janeiro. Representação que inclusive viria a garantir a existência de exceções administrativas para essa escola - como é o caso da carga horária extra de trabalho dos professores citada anteriormente. Não se pode colocar em jogo o prestígio da escola. A segunda possibilidade relaciona-se às histórias de vida $e$ aos interesses e necessidades dos professores de educação física que dirigem as equipes esportivas da escola. Se esses profissionais têm uma história esportiva marcante, possivelmente seus valores e ideais os levam a compreender competência profissional associada ao rendimento de seus alunos nas competições esportivas. E mais, mesmo os que não olhem por essa lente, provavelmente são vistos por ela. A competência profissional dos professores é 
avaliada, pela comunidade em geral, a partir do desempenho de seus alunos nas competições.

Outra característica que denota o que está em jogo nessas oficinas de esporte é a forma de divisão das turmas. Ela não é feita pelo ano de escolarização, mas por gênero e idade. As modalidades esportivas, assim como as categorias a serem trabalhadas nas oficinas durante o ano, são selecionadas de acordo com as intenções de participação da escola nos Jogos Estudantis do ano corrente. Em 2008, por exemplo, não aconteceu a formação das equipes da categoria mirim masculina e feminina de todas as modalidades. De acordo com a professora Márcia, mesmo não havendo a formação de equipes da categoria mirim para a disputa dos Jogos Estudantis, não é vedado aos alunos com idade correspondente a essa categoria a participarem das oficinas de esporte. Porém, durante o período de observação não foi constatado a presença de nenhum aluno ou aluna com idade compatível a essa categoria participando das oficinas de esportes.

No ano letivo de 2008, as oficinas de esportes oferecidas na escola foram: voleibol masculino, handebol masculino, handebol feminino, basquetebol masculino e basquetebol feminino. $O$ período de realização e o tempo de duração de cada uma das oficinas não foram préestabelecidos no início do ano, a cada semana a professora Márcia comunicava aos alunos quais modalidades seriam desenvolvidas no próximo sábado. Essa estratégia organizacional teve como objetivo priorizar as necessidades de treinamento das equipes para a participação nos Jogos Estudantis, seguindo seu calendário.

A professora Márcia ficou responsável pelas oficinas de voleibol masculino e handebol masculino e feminino, enquanto o professor Luciano ministrou as oficinas de basquetebol masculino e feminino. As estratégias metodológicas utilizadas pelos professores na transmissão dos conteúdos eram muito semelhantes. Geralmente as aulas estavam estruturadas da seguinte forma: dez minutos de aquecimento, 20 a 40 minutos de exercícios que visavam corrigir e apurar a técnica esportiva (os educativos) e 30 a 50 minutos de prática dirigida (o jogo em si). As atividades utilizadas durante o aquecimento eram bem diversificadas, iam desde brincadeiras até corridas em torno da quadra de jogo. Os educativos buscavam o aprimoramento do gestual motor envolvido na modalidade trabalhada. Por fim, no jogo os alunos eram divididos em equipes, das quais pelo menos uma era constituída somente por alunos das equipes esportivas da escola. As demais equipes eram formadas pelo restante da turma. Nesse momento, as atenções eram voltadas para a equipe constituída de alunos do time da escola. A eles eram passadas orientações táticas pertinentes às modalidades esportivas em questão, objetivando um melhor desempenho da equipe nas competições. Essa prioridade das atenções destinadas a apenas um número restrito de alunos novamente deixou evidente a ênfase no resultado, e não na educação esportiva de todos.

\section{A participação da escola investigada nos Jogos Estudantis}

Os Jogos Estudantis que constituíram o foco do presente estudo são promovidos pela prefeitura da cidade do Rio de Janeiro, cabendo sua organização e realização à Secretaria Municipal de Educação. Até o ano de 2008 aconteceram 17 ediçõos desses jogos, a escola investigada aparece em segundo lugar no ranking das escolas vencedoras dos jogos. Segunda a coordenadora dos Jogos Estudantis, Adelaine Campos, muitos dados estatísticos referentes à competição se perderam, pois a Secretaria Municipal de Esporte e Lazer, antiga organizadora dos jogos, não deixou esses registros. Apenas a partir do ano de 2002, quando a professora Adelaine assume a coordenação dos jogos, que esses dados passaram a ser registrados. Nessa direção, muitas informações aqui descritas são oriundas da memória de professores da escola investigada que participam dos jogos desde seus primórdios.

Os Jogos Estudantis da Cidade do Rio de Janeiro constituem-se em uma competição esportiva restrita a alunos matriculados regularmente na Rede Municipal de Ensino do Rio de Janeiro. Considerando os anos entre 2002 e 2008, mobilizaram uma média aproximada de 20.000 alunos, 1.200 professores e 380 unidades escolares. Os jogos acontecem no segundo semestre letivo de cada ano, iniciando-se no mês de junho, quando são realizados os congressos técnicos e as cerimônias de abertura dentro de cada CRE, e são encerrados em novembro, com as finais da segunda fase dos esportes de quadra. 
Os alunos participantes são distribuídos em categorias de acordo com suas faixas etárias, sendo permitida apenas a participação de alunos com idade entre nove e 15 anos. As modalidades esportivas disputadas são divididas em: modalidades de quadra (handebol, futsal, voleibol e basquetebol), atletismo, tênis de mesa e xadrez. As modalidades esportivas de quadra são disputadas em duas fases: na primeira, a disputa acontece entre escolas da mesma CRE; enquanto a segunda fase é disputada entre os primeiros colocados de cada CRE, para que assim se conheça o campeão municipal de cada modalidade. As modalidades de atletismo, xadrez e tênis de mesa são disputadas em fase única.

No ano 2008, a escola investigada disputou as seguintes modalidades e categorias: futsal masculino nas categorias infantil e infanto-juvenil, voleibol masculino nas categorias infantil e infanto-juvenil, voleibol feminino na categoria infantil, handebol masculino na categoria infantil, handebol feminino na categoria infantil, basquetebol masculino na categoria infantil e basquetebol feminino na categoria infantil. Além dessas modalidades de quadra, a escola participou ainda do xadrez e do tênis de mesa, ficando fora somente do atletismo. Sobre a não participação nas competições de atletismo, a professora Márcia nos disse que: "não adianta nós levarmos nossa equipe, é perda de tempo. Lá na Silveira [uma escola da rede], eles têm condições excepcionais, têm uma pista e contam até com patrocínio". Essas condições de infraestrutura que, segundo a professora, se traduzem no bom desempenho dessa escola na modalidade de atletismo fazem com que a escola investigada não invista nessa modalidade.

Assim como não houve formação de uma equipe de atletismo para a disputa dos Jogos Estudantis, também não foram formadas em 2008 equipes correspondentes à categoria mirim de ambos os sexos, como relatamos anteriormente. De acordo com a professora Márcia, esses problemas foram decorrentes do conturbado início de ano letivo, com relação às aulas de educação física, que tiveram os alunos das turmas do $6^{\circ}$ período - justamente aqueles que se encontram na faixa etária dessa categoria. Essas turmas passaram primeiramente por dois professores, que entraram de licença no início do ano letivo, e foram posteriormente assumidas pela professora Alexandra, que havia recém chegado à escola. Desse modo, as turmas permaneceram por um longo período sem aulas da disciplina. Observemos que esse caso, longe de ser isolado, reforça a tese de que as aulas regulares da disciplina educação física podem ser influenciadas pelos Jogos Estudantis (MILLEN NETO e FARIA, 2008). A construção social do currículo da educação física na escola investigada é marcada sobremaneira pelo discurso/voz do esporte de rendimento.

Outro fato que, segundo a professora Márcia, contribuiu para a não formação da categoria mirim em 2008 foi a sua ausência na escola no turno da tarde. ${ }^{5}$ Nesse sentido, não haveria um professor para iniciar esse trabalho com alunos, uma vez que, as professoras Daniella e Alessandra não realizam esse trabalho com equipes. O professor Frederico que também está na escola no turno da tarde, além de trabalhar exclusivamente com o futsal, não mostrou interesse e disponibilidade para realização desse trabalho com categoria mirim. Assim, ficou perceptível em nossas observações que, apesar do discurso curricular da educação física na escola ter sua marca no esporte escolar de rendimento, não há um consenso entre os professores sobre a identidade dessa disciplina na escola. As diferentes histórias de vida de profissionais e suas relações com o esporte determinam a constituições de suas disposições (LAHIRE, 2004).

No sentido de sanar o que consideravam um problema, e de fazer valer as suas disposições, os professores Márcia e Luciano, hoje os principais responsáveis pela organização das oficinas/equipes esportivas da escola, planejaram um novo arranjo de seus horários de trabalho para 2009: "ano que vem vamos tentar nos organizar para que a Márcia fique nas segundas e quartas de tarde e eu nas terças e quintas de manhã, assim terá sempre um de nós dois na escola" (Professor Luciano). Essa fala demonstra - poder que esses professores possuem no espaço escolar.

Um problema da dinâmica de participação dos jogos é o deslocamento de alunos e professores para os locais de competição. Durante nossas observações, o deslocamento foi realizado por ônibus de linha. Essa parece ser uma prática comum entre as escolas que participam dos jogos, pois não é oferecido pela Secretaria Municipal de Educação transporte próprio e tampouco uma ajuda de custo para a locação de ônibus ou vans. Esse problema faz parte do cotidiano da escola e já há algum tempo aparece nas pautas de reuniões da escola. Pudemos notálo no discurso de alguns professores e vê-lo impresso no Projeto Político Pedagógico (PPP) da escola. Vejamos o que está escrito nesse

\footnotetext{
5 As aulas das turmas do $6^{\circ}$ ano acontecem somente no turno da tarde e o horário da professora Márcia na escola, no ano
} 
documento, na seção que avalia as dificuldades encontradas no ano letivo anterior: "ausência de transporte para os alunos e professores nos Jogos Estudantis" (p.04). Outro ponto abordado no PPP, que se refere à educação física, trata das oficinas de esportes. Existe um controle sistemático da frequência dos alunos participantes por meio de chamada, e, tal controle está expresso no PPP: "Será cobrada assiduidade para garantir um rendimento satisfatório. Mais de duas faltas não justificadas no mês eliminarão 0 aluno [das oficinas]".

A presença de referências aos Jogos Estudantis e às oficinas de esportes no PPP denota a importância que esse evento e, consequentemente, a disciplina educação física, tem na formação da identidade da escola investigada. A voz da legitimação através do esporte de rendimento na escola, com a seleção de talentos e formação de atletas, faz-se valer no discurso da comunidade escolar. Inclusive a reformulação do PPP, desenvolvida em 2008, indica a educação física como um dos elementos norteadores dos projetos da escola investigada.

Os dias e horários da competição se configuraram como mais uma problemática a se destacar na dinâmica dos Jogos Estudantis e sua relação com o cotidiano da escola. As partidas dos Jogos Estudantis da Cidade do Rio de Janeiro aconteceram, em 2008, de segunda a sexta-feira, nos períodos da manhã e da tarde. Nesse sentido, os alunos-competidores se ausentaram das salas de aula para participar dos jogos.

\section{Considerações Finais}

A leitura dos dados coletados no transcorrer da investigação nos permitiu inferir algumas considerações com relação à voz do esporte de rendimento veiculado na escola investigada pelos Jogos Estudantis do Município do Rio de Janeiro. Observe-se que o esporte escolar de rendimento é central no discurso curricular e na identidade dessa escola no mercado das escolas da rede municipal. Esse fato auxilia a entender como a escola conseguiu um tipo de exceção administrativa para remunerar seus professores pelo trabalho extra que realizam com as oficinas de esporte. Tal êxito sem dúvida se relaciona com o prestígio da escola nos jogos e a rede social de seus dirigentes.

de 2008, ficou reservado às segundas e terças-feiras na parte da manhã.
Como vimos no contexto da pesquisa, a obtenção de bons resultados nos jogos não significa a distribuição de maiores oportunidades de práticas, experiências e de novas aprendizagens esportivas para todos os alunos. Os não escolhidos para as equipes não receberam nenhum tipo de apoio pedagógico para realizarem seus desejos de melhorarem suas competências esportivas. Destacamos que, apesar de entendermos que o currículo não pode tornar todas as atividades escolares compulsórias, a missão da escola é dar oportunidades de desenvolvimento para aqueles que desejam desenvolver suas aptidões, independente do estágio de partida.

Consciente da repercussão positiva na imagem da instituição, a escola investigada investe na veiculação desse evento. Informações sobre o evento e sobre o sucesso da escola foram divulgadas interna - através de cartazes e externamente - em diferentes periódicos do município.

Como o que está em jogo é muito importante a imagem/identidade da escola e a competência de seus profissionais -, a proposta pedagógica de se dar uma formação esportiva para todos os alunos acaba suprimida em função das vitórias esportivas. Como observamos no espaço da escola, essa visão - do alto rendimento esportivo - não é consenso entre os docentes de educação física. Todavia, a voz dissonante é pouco audível no espaço curricular e na comunidade escolar. Assim, a influência dos Jogos Estudantis na construção social do currículo na escola investigada pode fornecer elementos para afirmação de uma identidade positiva para dentro e para fora, ao mesmo tempo em que tal proposta não oferece oportunidades de democratizar novas aprendizagens para aqueles que almejam participar das equipes, mas não são escolhidos.

\section{Referências}

BAUER, M. W. Análise de conteúdo clássica: uma revisão. In: BAUER, Martin W.; GASKELL, G. (Orgs.). Pesquisa qualitativa com imagem texto e som: um manual prático. Petrópolis: Vozes, 2002.

BETTI, M. Educação física e sociedade: a educação física na escola brasileira de $1^{\circ}$ e $2^{2}$ 으. graus. São Paulo: Movimento, 1991. 
BRACHT, V. Educação física e aprendizagem social. Porto Alegre: Magister, 1992.

BRASIL. Secretaria de Educação Fundamental. Parâmetros Curriculares Nacionais. Brasília: MEC/SEF, 1998.

COSTA, V. L. M. Educação Física no 1ำ grau: modelo de reprodução ou perspectiva de transformação? São Paulo: IBRASA, 1987.

DAOLIO, J. Da cultura do corpo. Campinas, SP: Papirus, 1995.

DAOLIO, J. Educação física brasileira: autores e atores da década de 1980. Campinas, SP: Papirus, 1998.

DARIDO, S. C. Educação física na escola: questões e reflexões. Araras, SP: Topázio, 1999.

FREIRE, J. B. Educação de corpo inteiro: teoria e prática da educação física. São Paulo: Scipione, 1989.

GEERTZ, C. A interpretação das culturas. Rio de Janeiro: LTC, 1989.

GIDDENS, A. Modernidade e identidade. Rio de Janeiro. Jorge Zahar, 2002.

GOIS JUNIOR, E. O século da higiene: uma história de intelectuais da saúde. 2003. Tese (Doutorado em Educação Física) - Universidade Gama Filho, Rio de Janeiro, 2003.

GOODSON, I. F. Currículo: teoria e história. 8. ed. Petrópolis: Vozes, 2008.

KUNZ, E. Educação Física: ensino \& mudança. ljuí, RS: Unijuí, 1991.

KUNZ, E. Transformação didático-pedagógica do esporte. ljuí, RS: Unijuí, 1994.

LAHIRE, B. Retratos sociológicos: disposições e variações individuais. Porto Alegre: Artmed, 2004.

LOVISOLO, H. A arte da mediação. Rio de Janeiro: Sprint, 1995.

MARCELLINO, N. C. Lazer e educação.

Campinas, SP: Papirus, 1987.

MEDINA, J. P. S. A educação física cuida do corpo... e "mente": bases para a renovação e transformação da educação física. Campinas, SP: Papirus, 1983.

MILLEN NETO, A. R.; FARIA, C. N. Políticas públicas de fomento ao esporte escolar no município de Volta Redonda (RJ). Revista Científica do Centro Universitário de Barra Mansa, Barra Mansa, v.10, n.20, p.66-77, dez. 2008.

OLIVEIRA, V. M. O que é Educação Física. São Paulo: Brasiliense, 1983.

OLIVEIRA, V. M. Educação Física humanista. Rio de Janeiro: Ao Livro Técnico, 1985.

RESENDE, H. G.. A educação física na perspectiva da cultura corporal: uma proposição didático-pedagógica. 1992. Tese (Livre Docência) - Universidade Gama Filho, Rio de Janeiro, 1992.

SOARES, C. L. et al. Metodologia do ensino da educação física. São Paulo: Cortez,1992.

TANI, G. et al. Educação física escolar: fundamentos de uma abordagem desenvolvimentista. São Paulo: EPU/EDUSP, 1988.

Endereço:

Alvaro Rego Millen Neto

Universidade Gama Filho

Rua José Maria da Cruz, 117/304

Barra Mansa RJ Brasil

27330-280

Telefone: (24) 8818.7071

e-mail: amillen@gmail.com

Recebido em: 14 de julho de 2010.

Aceito em: 18 de março de 2011.

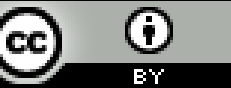

Motriz. Revista de Educação Física. UNESP, Rio Claro, SP, Brasil - elSSN: 1980-6574 - está licenciada sob Creative Commons - Atribuição 3.0 